\title{
A school based intervention to reduce television use decreased adiposity in children in grades 3 and 4
}

Robinson TN. Reducing children's television viewing to prevent obesity. A randomized controlled trial.JAMA 1999 Oct 27;282:1561-7.

QUESTION: Can a school based intervention aimed at reducing television and videotape viewing and use of video games decrease adiposity in children in grades 3 and 4 (approximate age 9 y)?

\section{Design}

7 month, randomised (allocation concealed*), blinded (outcome assessors and statisticians*), controlled trial.

\section{Setting}

2 public elementary schools in a single school district in San Jose, California, USA.

\section{Participants}

198 of 227 eligible children in grades 3 and 4 had parental consent to participate. 192 children (97\%) (mean age 9 y) completed both the baseline and post-intervention assessments.

\section{Intervention}

The 2 schools were matched on sociodemographic and scholastic variables. One school (106 eligible children) was allocated to implement an intervention to reduce television use by limiting access to television sets, budgeting watching or playing time, and more selective use. 18 lessons of 30-50 minutes each were incorporated into the standard curriculum and taught by regular classroom teachers who received special training. The second school $(n=121$ eligible children) received the usual curriculum (control group).

\section{Main outcome measures}

Main outcome was adiposity (body mass index [BMI]) measured at baseline (September 1996) and after the intervention (April 1997). Secondary outcomes included subcutaneous fat (triceps skinfold thickness); body fat distribution (waist-to-hip ratio); child reported time spent watching television, watching videos, or playing video games; consumption of high fat foods; frequency of eating breakfast and dinner in front of a television; proportion of time eating a snack during media use; physical activities; and cardiorespiratory fitness (maximal, multi-stage, $20 \mathrm{~m}$ shuttle run test).

\section{Main results}

Analysis was by intention to treat. BMI, skinfold thickness, waist circumference, and hip circumference increased in both groups (as expected for children of this age). However, children in the intervention group had relative decreases in BMI $(p=0.002)$, triceps skinfold thickness $(\mathrm{p}=0.002)$, waist-to-hip ratio $(\mathrm{p}<0.001)$, television viewing $(\mathrm{p}<0.001)$, video game use $(p=0.01)$, and frequency of eating meals in front of a television $(p=0.01)$ compared with children in the control group (table). The groups did not differ for videotape viewing, daily servings of high fat foods, physical activity levels, or cardiorespiratory fitness.

\section{Conclusion}

A school based intervention aimed at reducing television and video game use reduced adiposity in children in grades 3 and 4 .
Curriculum based intervention to reduce television use v usual curriculum in grades 3 and 4 children

\begin{tabular}{ll} 
Outcomes & Adjusted change $(95 \% \mathrm{Cl}) \dagger$ \\
\hline Body mass index $\left(\mathrm{kg} / \mathrm{m}^{2}\right)$ & $-0.45(-0.73$ to -0.17$)$ \\
\hline Triceps skinfold thickness $(\mathrm{mm})$ & $-1.47(-2.41$ to -0.54$)$ \\
\hline Waist-to-hip ratio & $-0.02(-0.03$ to -0.01$)$ \\
\hline Television viewing $(\mathrm{h} / \mathrm{wk})$ & $-5.53(-8.64$ to -2.42$)$ \\
\hline Video game use (h/wk) & $-2.54(-4.48$ to -0.60$)$ \\
\hline $\begin{array}{l}\text { Meals in front of television } \\
\text { (0-3 pt scale) }\end{array}$ & $-0.54(-0.98$ to -0.12$)$ \\
\hline
\end{tabular}

†Differences between groups after adjustment for baseline value, age, and sex. Negative values indicate a relative decrease in the outcome for the intervention group compared with the control group.

*Information provided by author.

\section{COMMENTARY}

Interventions to reduce childhood obesity have met with low levels of interest probably because of the stigma associated with being different or attending a special class. The idea of a curriculum based intervention designed to reach all students is appealing. The study by Robinson found that children who received a curriculum based intervention aimed at television use made lifestyle changes that resulted in decreased BMI compared with students who received the usual curriculum.

Study strengths include the randomised, controlled design and adjustment in the analysis to account for cluster randomisation. To avoid the possibility of teachers delivering additional interventions to prevent obesity, they were kept blinded to the primary hypothesis of the study (ie, that children exposed to the television reduction intervention would significantly decrease their levels of adiposity). Study weaknesses include limited generalisability (only 2 schools were included) and the short period between the intervention and follow up $(7 \mathrm{mo})$.

The implications for public health or school boards are important. Given the increase in childhood obesity and the associated risk of continued adiposity into adulthood, perhaps school curricula could incorporate interventions designed to reduce media use.

Having worked with obese children for the past 16 years in a private practice where finances prohibit many children from participating in special programmes, I am excited about the idea of classroom based interventions as a way to reach the masses.

Kathy Shadle James, RN, NP, DNSc Assistant Professor of Nursing Hahn School of Nursing and Health Sciences University of San Diego San Diego, California, USA 